\title{
STRENGTH OF BONDS BETWEEN ICE GRAINS AFTER SHORT CONTACT TIMES
}

\author{
By H. GubleR \\ (Eidg. Institut für Schnee- und Lawinenforschung, 7260 Weissfluhjoch/Davos, Switzerland)
}

\begin{abstract}
The tensile force required to break bonds between ice grains after short contact times $(1-500 \mathrm{~s})$ is measured as a function of temperature and contact pressure. The results indicate a sharp increase of the tensile load capacity of bonds after short contact times near the melting point and a maximum rate of increase of the load capacity at $-5^{\circ} \mathrm{C}$. The initial state of sintering is modelled, assuming viscous surface flow and plastic deformation as the main mechanisms.
\end{abstract}

RÉSumÉ. Résistance à la traction des ponts entre des billes de glace après des temps de contact courts. La force de traction nécessaire pour rompre les ponts entre des billes de glace, après des temps de contact courts (1-500 s), est mesurée en fonction de la temperature et de la pression au contact. Les résultats montrent une augmentation sensible de la portance des ponts après des brefs temps de contact à des températures voisinant le point de fusion. ainsi qu un taux d'accroissement maximum de la portance a $-5^{\circ} \mathrm{C}$. La phase initiale de la croissance des ponts est simulee en admettant un flux visqueux à la surface et une déformation plastique au contact.

ZuŚmmenfassung. Festigkeit von Bindungen zwischen Eiskörnern nach kurzen Kontaktzeiten. Die Tragfähigkeit von Bindungen zwischen Eiskörnern nach kurzen Kontaktzeiten (1-500 s) wird in Abhängigkeit von der Temperatur und dem Kontaktdruck gemessen. Die Resultate zeigen einen deutlichen Anstieg der Tragfähigkeit der Bindungen nach kurzen Kontaktzeiten bei Temperaturen nahe dem Schmelzpunkt sowie eine maximale Zunahmesrate der Tragfähigkeit bei $-5^{\circ} \mathrm{C}$. Die Anfangsphase des Zusammensinterns wird unter Annahme von viskosem Oberflächenfluss und plastischer Deformation simuliert.

\section{INTRODUCTION}

The growth of sintered bonds between ice spheres has been studied (Nakaya and Matsumoto, 1954, Jensen, unpublished; Hosler and Hallgren, 1960; Kingery, 1960; Kuroiwa, 1961; Hobbs and Mason, 1964). Hobbs and Mason (1964), concluded from the timedependence of the growth of the bonds and from the measured absolute value of the diffusion constant that bond growth is caused primarily by the transport of water molecules through the vapour phase. However, the strength of bonds in the initial stage of sintering (after short times of contact between the grains) cannot be explained by this transport mechanism.

The strength of snow is largely dependent on intergranular structure and on the strength of the bonds between the grains. Deformation of snow often causes fracturing of some of the bonds and the generation of new contact points. Deformation changes the intergranular structure (Kry, 1975[a] and [b]; St. Lawrence and Bradley, [1975]; Gubler, 1978; St. Lawrence, 1980). The relationships between stress, strength and strain, and strain-rate depend strongly on the strength development in the new contact points.

In order to improve our knowledge of the initial stage of sintering, we designed an experiment to measure the strength of bonds between ice grains after contact times of 1 to $1000 \mathrm{~s}$ as a function of contact pressure, temperature, and stress rate. The experimental results are explained by the flow of water to the bond neck in the liquid-like surface layer of ice (Weyl, 1951; Fletcher, 1968: Kvlividze and others, 1973; Golecki and Jaccard, 1977; Gilpin, 1979), the deformation of 
the spheres at the contact point, freezing of the liquid-like layer in the contact volume, and local pressure melting.

Strength increase of snow caused by sintering for short time periods ( $1-1000 \mathrm{~s})$ at new contact points is the basis for deterministic models for locking mechanisms in avalanches. blowing snow, snow compaction, and snow milling.

\section{APPARATUS}

The basic experimental arrangement is shown in Figure 1. The tips of two ice cones are slowly brought into contact and are compressed using forces which range from 0 to $0.1 \mathrm{~N}$. One of the ice cones (diameter of the base: $20 \mathrm{~mm}$, point angle $45^{\circ}$, tip curvature radius $0.5 \mathrm{~mm}$ ) is mounted on a piezoelectric force transducer (sensitivity $<10^{-3} \mathrm{~N}$ ). The second, moveable cone is fixed to a steel-aluminium axle which is suspended by thin threads. The forces (in compression and in tension) are applied to this rod by electromagnetic coils. The system is placed in a sealed container. The container bottom is partially covered with granular snow and can be heated with a temperature-controlled heater to maintain the desired relative humidity of between 90 and $100 \%$ in the container. The experimental area with the two cones is in addition protected by a small "Plexiglas" box. Temperatures are measured with an absolute accuracy of $\pm 0.1^{\circ} \mathrm{C}$ at different points around the cones and inside the ice cones near their tips (Fig. 1). The polycrystalline ice cones were slowly frozen in brass moulds from their base to the tip under a temperature gradient using outgassed, distilled water. The electronic arrangement achieves an automatic soft contact of the two cone tips and can apply a large variety of stress functions in tension and compression to the contact between the cones.

\section{Measurements}

Recordings of bond strength were made at temperatures between $-0.2{ }^{\circ} \mathrm{C}$ and $-44^{\circ} \mathrm{C}$. Measurements with two different pairs of cones were made at each temperature. After the cones were carefully brought into contact, a uniform force pulse of duration $t$ and amplitude $10^{-2} \mathrm{~N}$

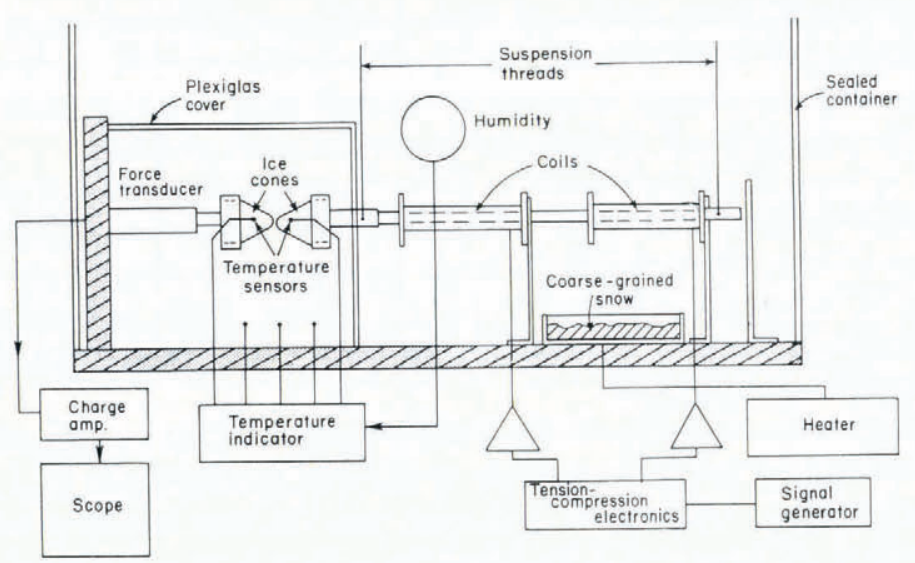

Fig. 1. Basic experimental setup. 
was applied in compression. The compression pulse was immediately followed by a tensile force applied at a rate of $2 \times 10^{-2} \mathrm{~N} \mathrm{~s}^{-1}$ until the bond fractured. The cones were kept apart for $60 \mathrm{~s}$ between consecutive experiments to allow the cone tips to recover. The duration $t$ of the compression pulse was varied according to the following pattern:

$$
t=2,5,10,20,40,80,160,320 \mathrm{~s}
$$

alternately forward and backward. Each run consisted of at least three patterns of the compression pulse lengths and included one change of the cone pair. Alternation of the start of the runs between the compression pulses of the longest or the shortest duration is important to test for any possible hysteresis in the recorded tensile fracture forces.

\section{RESULTS}

The recordings of the fracture forces type A (Table I) were plotted as a function of the compression pulse duration $t$ for each run and fitted to a power law:

$$
\begin{aligned}
& F_{T}=q \alpha t^{\beta} \\
& q=1 s^{-\beta},
\end{aligned}
$$

$\alpha$ and $\beta$ are temperature- and geometry-dependent variables. The power law was chosen because all of the currently proposed growth laws for sintered bonds between ice grains (Hobbs, 1974) can be expressed as power laws of the time of contact of the ice spheres. For each run three pairs of parameters $\alpha$ and $\beta$, their mean errors, correlation coefficients, and $t$-values (Student's $t$-test) were calculated, $\alpha \uparrow, \beta \uparrow$ for increasing compression pulse length $t, \alpha \downarrow, \beta \downarrow$ for decreasing $t$ and the mean values $\bar{\alpha}, \bar{\beta}$ for the complete run.

The following estimates were used for the determination of the relative error of $\alpha$ and $\beta$ :

$$
r_{\alpha}=\frac{\sigma_{\mathrm{F}}}{F_{T}(t=1 \mathrm{~s})}, \quad r_{\beta}=\frac{\ln \left(1+r_{\alpha}\right)}{\beta \ln \left(t_{\max } / t_{\min }\right)}=\frac{r_{\alpha}}{5.1 \beta}
$$

where $\sigma_{\mathrm{F}}$ is the mean error of the smoothed fracture force $F_{T}$. The determination of the compression pulse duration $t$ is assumed to be error free. $t_{\min }=2 \mathrm{~s}$ and $t_{\max }=320 \mathrm{~s}$ are the lower and higher limits of $t . \beta\left(1 \pm r_{\beta}\right)$ corresponds approximately to the lowest and largest slope angles

Table I. Details of measurements

\section{Type of measurement}

A Tensile fracture force at $2 \times 10^{-2} \mathrm{~N} \mathrm{~s}^{-1}$; compression pulse length* $(2-300) \mathrm{s}$; compression $10^{-2} \mathrm{~N}$

B Tensile fracture force at $2 \times 10^{-2} \mathrm{~N} \mathrm{~s}^{-1}$; compression pulse length $20 \mathrm{~s}$; compression $(<1,5,10,20,40,80) \times 10^{-3} \mathrm{~N}$

\begin{tabular}{|c|c|c|}
\hline $\begin{array}{l}\text { Number of } \\
\quad \text { runs }\end{array}$ & \multicolumn{2}{|c|}{$\begin{array}{c}\text { Temperature range } \\
{ }^{\circ} \mathrm{C}\end{array}$} \\
\hline & Upper & Lower \\
\hline 62 & -0.16 & -44 \\
\hline 8 & -1.5 & -38 \\
\hline 3 & -1.5 &,-21 \\
\hline
\end{tabular}

$\mathrm{C}$ Tensile fracture force at $(1-150) \times 10^{-2} \mathrm{~N} \mathrm{~s}^{-1}$; compression pulse length $20 \mathrm{~s}$; compression $10^{-2} \mathrm{~N}$
* In some runs the compression-pulse duration was increased to $3000 \mathrm{~s}$. 
$\beta$ in a log plot of the fracture force versus compression pulse duration $t$ (Fig. 2). The mean correlation coefficient for all fits is 0.9 , the extreme values are 0.5 and 0.99 . The corresponding confidence levels are always higher than $95 \%$. Results for $\beta$ and $\alpha$ are plotted in Figures 3 and 4 as a function of the negative temperature $\delta\left[\left|{ }^{\circ} \mathrm{C}\right|\right]$. The mean relative errors are $\bar{r}_{\alpha}=0.22-0.28$ (range for $\alpha \uparrow, \alpha \downarrow, \bar{\alpha}$ ), $\bar{r}_{\beta}=0.17$, the corresponding most probable errors are $\hat{r}_{\alpha}=0.13-0.2$, $\hat{r}_{\beta}=0.06-0.11$. The error distributions are not symmetric but are skewed to larger relative errors caused by enlarged errors at high temperatures.

The relationship between the fracture force and the compression force is roughly linear (measurements type $B$, table I). The gradient is about 1 , independent of temperature (see page 471). All measurements show a residual fracture force for zero contact pressure.

The fracture force does not significantly depend on stress rate (measurements type C, Table I).

\section{DISCUSSION OF THE RESULTS}

The hysteresis of the fracture force at increasing and decreasing compression pulse durations is caused by surfaces being incompletely recovered. No distortion of the cone tip surface could be seen under an optical microscope a few seconds after the separation of the cones. The hysteresis of the mean fracture force is equal to or less than the mean error of a single fit. The mean relative hysteresis of the exponent $\beta$ is 0.15 . Above $-10^{\circ} \mathrm{C}$ the higher exponents are related to measurements with increasing compression pulse durations $t$, the lower exponents to recordings at decreasing $t$. Below $-10^{\circ} \mathrm{C}$ no significant hysteresis has been observed.

The parameter $\beta$ has its highest value in the temperature range $-1^{\circ} \mathrm{C}$ to $-5^{\circ} \mathrm{C}$, falls to a slightly lower constant value at lower temperature but above $-1{ }^{\circ} \mathrm{C}$ decreases sharply reaching zero at the melting point. The fracture-force proportionality parameter $\alpha$ increases sharply above $-2{ }^{\circ} \mathrm{C}$. Near the melting point, the fracture force reaches a high asymptotic value after short contact times $(1-30 \mathrm{~s})$. The increase of the fracture force with contact time is highest at temperatures of about $-1{ }^{\circ} \mathrm{C}$ to $-5^{\circ} \mathrm{C}$. Below $-10^{\circ} \mathrm{C}$ the magnitude of the tensile fracture force

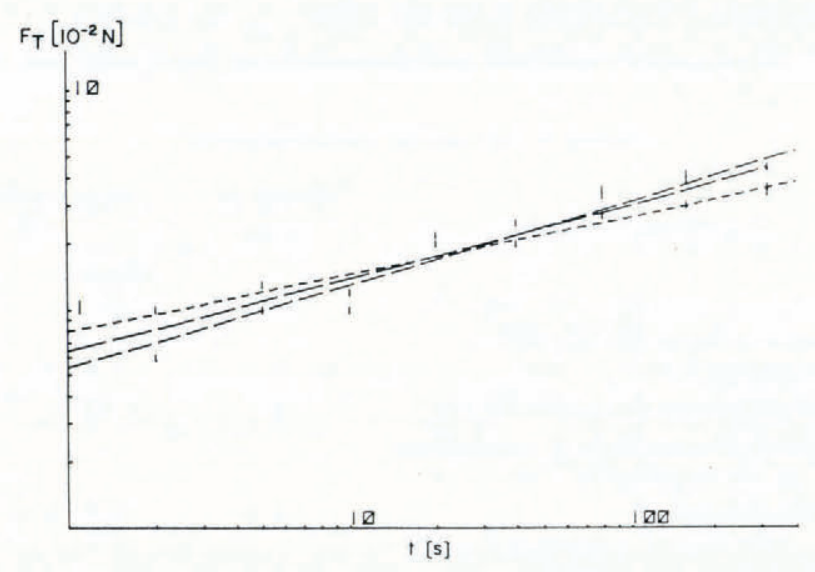

Fig. 2. Fracture force versus compression pulse length t at a temperature of $-10^{\circ} \mathrm{C}$. The straight lines are the power law fits for increasing and decreasing $t$ and the whole run. 


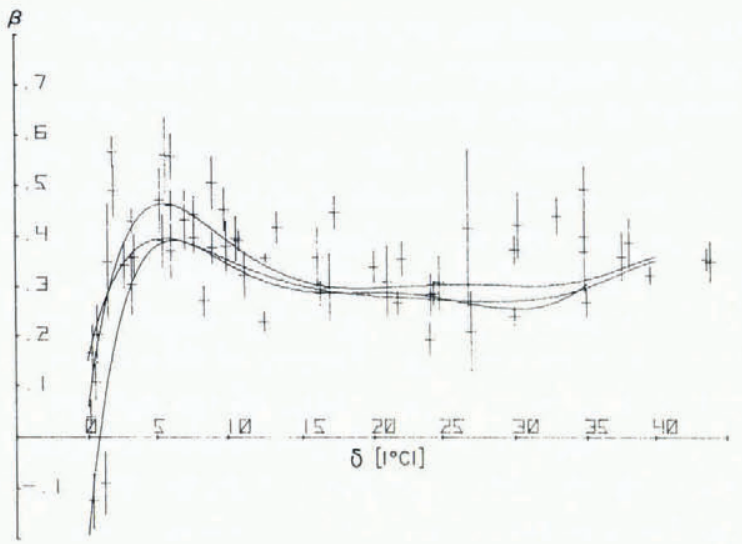

Fig. 3. $\beta \uparrow$ as a function of the negative temperature $\delta\left[\left.\right|^{\circ} \mathrm{C} \mid\right]$ fitted with a seventh order polynomial. The corresponding curves for $\beta \downarrow$ and $\bar{\beta}$ are also included.

decreases only slightly with decreasing temperature; the growth rate of the bonds remains almost constant.

\section{Theory'}

Assumptions of the model

The main assumption in the model is the existence of a liquid-like layer on ice surfaces. This liquid-like layer has been proposed by several authors (Faraday, 1859; Weyl, 1951; Kingery, 1960; Fletcher, 1968; Jellinek, 1972; Kvlividze and others, 1973; Golecki and Jaccard, 1977; Maeno and Nishimura, 1978; Gilpin, 1979). Fletcher is the only worker who has tried to develop a quantitative theory of the surface structure of ice; both his attempts have been shown to be

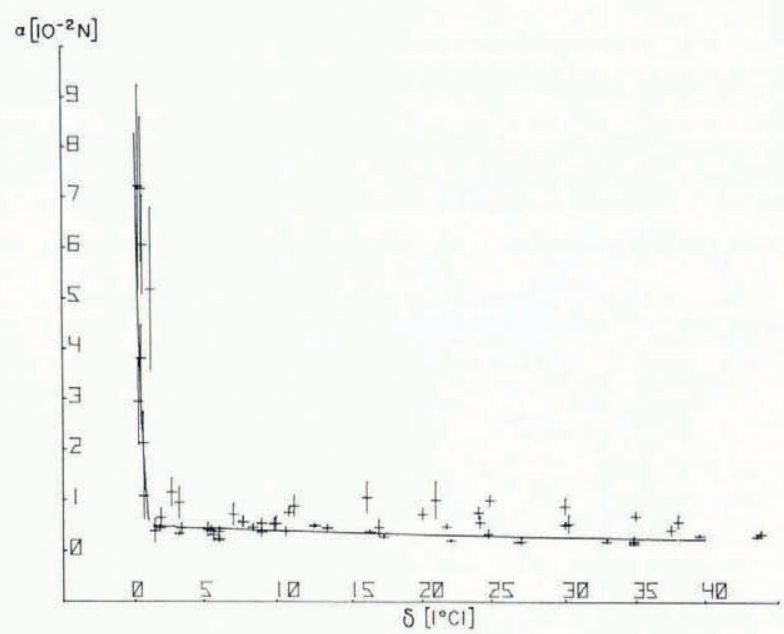

Fig. 4. $\alpha \uparrow$ as a function of $\delta$ fitted with a logarithmic function of $\delta$ for $\delta<1$ deg and a third degree polynominal $\delta \geqq 1$ deg. 
incomplete. His theories predict surface thicknesses of the order of magnitude of some $10^{-9} \mathrm{~m}$ with sharp increases as temperature approaches the melting point. Jellinek (1972), using mechanical testing, estimated the surface thickness to be $9 \times 10^{-8} \mathrm{~m}$ at $-1.8^{\circ} \mathrm{C}$. Golecki (1977) measured the thickness of the disordered surface as a function of temperature using proton channelling. Measuring the thickness of the transition layer as a function of temperature shows a logarithmic dependence on the absolute value of the negative temperature in $\left|{ }^{\circ} \mathrm{C}\right|$ ( $\approx \log \left(\right.$ const. $\left.\delta\left[{ }^{\circ} \mathrm{C}\right]\right)$ ) similar to that stated in Fletcher's original theory (Fletcher, 1962) but with a 20-fold larger slope. Golecki's measurement is also in fair agreement with Jellinek's mechanical estimate. The nuclear magnetic resonance measurements of Kvlividze and others (1973) show a significantly increased mobility of a small percentage of the molecules in dispersed ice. The mobility was found to be comparable to the mobility of molecules in liquid water. Kvlividze has shown that the high mobile molecules are concentrated at the ice-gas interface.

With these results as background, I propose the following model: If two spherical ice particles are in contact, the liquid-like layers start to freeze in the contact area. Surface energy together with the large difference in the curvatures between the neck and surface points on the spheres outside the contact area give rise to a pressure gradient along the transition layer. This pressure gradient caused by the surface tension creates in the transition layer a viscous flow toward the bond neck. It is further assumed that the liquid-like layer retains its equilibrium thickness in the source region independent of the flow. The flow distance $L$ is the mean distance at which liquid contributes to the bond. $L$ is estimated in different ways: (a) to be a constant value; (b) as the distance between points of minimum and maximum pressure; (c) as a function of a relaxation time describing the phase change at the solid-liquid interface. If the particles are compressed, the spheres deform plastically until the stresses in the contact region decrease below the yield stress. In the initial stage of contact under compression, pressure melting contributes significantly to the bond volume at high temperatures.

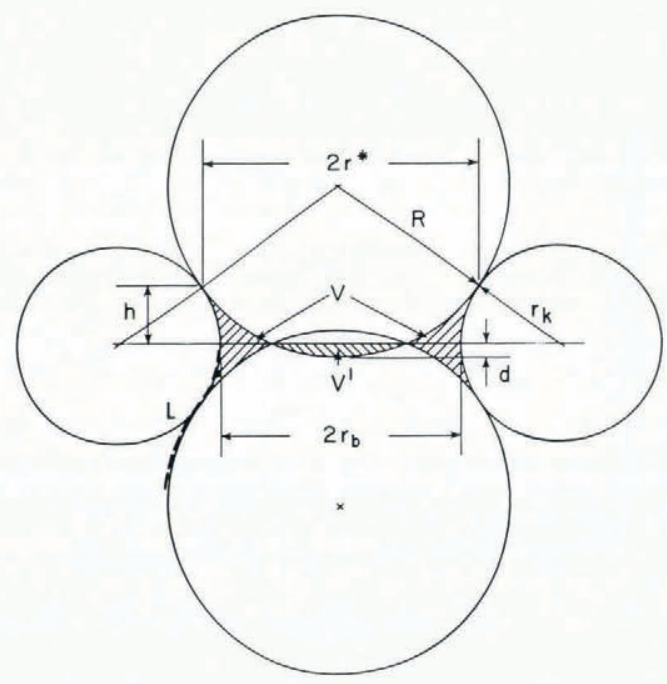

Fig. 5. Bond geometry. 


\section{Bond geometry}

The idealized parameters are defined in Figure 5. The curvature of the neck surface is approximated by a circle of radius $r_{K}$.

$$
r_{K}=\frac{r_{\mathrm{b}}^{2}-2 R d+d^{2}}{2\left(R-r_{\mathrm{b}}\right)}
$$

where $r_{\mathrm{b}}=$ bond radius in the neck midplane

$R=$ radius of curvature of the ice particles in the contact region

$d=$ penetration depth of the particles because of plastic deformation.

The radius of the bond at the neck boundary $r^{*}$ is

$$
r^{*}=\frac{r_{\mathrm{b}}+r_{K}}{R+r_{K}} R
$$

The volume $V^{\prime}$ of the sphere cut is

$$
V^{\prime}=\frac{1}{3} \pi d^{2}(3 R-d) .
$$

The total bond volume $V$ is given by the following expressions

$$
\begin{gathered}
V=2 \pi\left\{\left(c^{2}+r_{K}^{2}\right) y-\frac{1}{3} y^{3}-c y\left(r_{K}^{2}-y^{2}\right)^{1 / 2}+r_{K} \arcsin y / r_{K}-\right. \\
\left.-\frac{1}{3}(y+d)^{2}(3 R-y-d)+\frac{1}{3} d^{2}(3 R-d)\right\}, \\
y=\frac{(R-d) r_{K}}{R+r_{K}}, \\
c^{2}=2 R r_{K}+r_{K}^{2}+2 R d-d^{2} .
\end{gathered}
$$

The curvature $k_{\mathrm{b}}$ in the mid-plane cross-section of the bond is

$$
k_{\mathrm{b}}=-\frac{1}{r_{K}}+\frac{1}{r_{\mathrm{b}}}
$$

The curvature of the particle in the contact region is

$$
k_{s}=\frac{2}{R} \text {. }
$$

\section{Driving pressure gradient}

The pressure difference $\Delta p$ over the flow distance $L$ is approximated by

$$
\Delta p=\gamma_{\mathrm{LV}}\left(k_{s}-k_{\mathrm{b}}\right)=\gamma_{\mathrm{LV}}\left(2 / R-r_{\mathrm{b}}^{-1}+r_{k}^{-1}\right),
$$

$\gamma_{L V}$ is the surface energy of the transition layer.

Under the assumption of a laminar Newtonian flow with a constant pressure gradient parallel to the surface layer and constant flow height determined by the equilibrium conditions for the disordered surface layer, the rate of volume increase $\mathrm{d} V / \mathrm{d} t$ of the bond volume $V$ is (contribution of both particle surfaces considered)

$$
\frac{\mathrm{d} V}{\mathrm{~d} t}=2 \frac{l^{3}}{6} \frac{\gamma_{\mathrm{LV}}}{\eta_{\mathrm{L}}} \frac{1}{L} \frac{\Delta p}{\gamma_{\mathrm{LV}}} 2 \pi r^{*}
$$


where $l$ is the equilibrium thickness of the liquid-like layer and $\eta_{\mathrm{L}}$ is the viscosity of the surface layer.

\section{FLOW DISTANCE $L$}

The estimation of the flow distance is critical. The dependence of the bond radius on the contact time and particle diameter is partially determined by the approximation of the flow distance. The simplest assumption is a constant flow distance $L$, independent of geometry and material flux (case a):

$$
L=\text { constant }
$$

As we will see later, only the flow distance multiplied by the viscosity of the surface layer can be estimated from the experiment.

In a second attempt, the flow distance is chosen to be twice the distance over which the driving pressure gradient is established by the surface energy and the bond geometry (case b). For this case the flow distance depends on the actual bond geometry and the grain diameter:

$$
L=2 r_{K} \arcsin \frac{R-d}{R+r_{K}} .
$$

A third possibility is to assume a constant relaxation time at the ice-liquid interface

$$
\left.\frac{i}{\tau} \text { (ice } \rightarrow \text { liquid }\right)=\text { constant }
$$

where $i$ is a typical intracrystal molecular distance $\approx 5 \times 10^{-10} \mathrm{~m}$ and $\tau$ is the relaxation time which controls the phase change between the ice structure and the liquid structure $\approx 10^{-3} \mathrm{~s}$ (Bilgram and Güttinger, 1978).

The flow rate $\dot{Q}$ is given by

$$
\dot{Q}=A i / \tau
$$

where $A$ is the source area and

$$
A \approx 2 \pi\left(2 L-r_{\mathrm{b}}\right)^{2} \text { for } r_{\mathrm{b}} \ll R .
$$

The flow length is now a function of the flow rate:

$$
L=\frac{1}{2 \sqrt{2 \pi}} \dot{Q}^{1 / 2}\left(\frac{i}{\tau}\right)^{-1 / 2}+\frac{r_{\mathrm{b}}}{2} .
$$

\section{Creep under contact stress using the indenter-hardness concept}

The yield stress $\sigma_{\mathrm{y}}$ for creep of polycrystalline ice is given by Hobbs (1974)

$$
\sigma_{\mathrm{y}}=\sigma_{0} c t^{-1 / n} \exp \left(\frac{E}{n k T}\right),
$$

with $E=2.6 \times 10^{-19} \mathrm{~J}, n=3.9$ for $T \geq 263 \mathrm{~K}, E=1.2 \times 10^{-19} \mathrm{~J}, n=4.4$ for $T<263 \mathrm{~K}$, $k=$ Boltzmann constant: $1.38 \times 10^{-23} \mathrm{~J} \mathrm{deg}^{-1}$, and $t$ is the time of compression; the constant $c$ has the dimensions $\left[\mathrm{s}^{1 / n}\right]$. 
$\sigma_{0}$ is determined by experiment and is of the order of $10^{6} \mathrm{~N} \mathrm{~m}^{-2}$ for $t=1 \mathrm{~s}, T=270 \mathrm{~K}$. For the times $t$ after the application of the compression force, the reciprocal penetration of the cone tips is calculated as a function of the corresponding yield stress:

$$
F=\pi r^{\prime 2} \sigma_{0} c t^{-1 / n} \exp \left(\frac{E}{n k T}\right),
$$

$r^{\prime}$ is the effective radius of the stress-conducting part of the bond and $F$ is the compression-force pulse amplitude.

The bond radius in the absence of material flux $r_{\mathrm{c}}$ is approximately

$$
r_{\mathrm{c}}=\sqrt{2 R d} ; \quad d \ll R .
$$

The compression force $F_{\mathrm{c}}$ acting on the cross-sectional area $\pi r_{\mathrm{c}}^{2}$ is deduced from the total compression force $F$ with the assumption of equal yield stress for the cone ice and the bond ice:

$$
F_{\mathrm{c}} \approx F \frac{\pi r_{\mathrm{c}}^{2}}{\pi r_{\mathrm{b}}^{2} \text { (frozen) }} .
$$

From Equations (15) and (16) the penetration $d$ is

$$
d=\frac{F_{\mathrm{c}}}{\pi 2 R c \sigma_{0}} t^{+1 / n} \exp \left(\frac{-E}{n k T}\right) .
$$

The corresponding contribution to the total bond volume is (Equation 5)

$$
V=\frac{2}{3} \pi d^{2}(3 R-d) \text {. }
$$

\section{Pressure melting}

The depression of the melting point $\Delta T_{\mathrm{M}}$ as a function of pressure is

$$
\Delta T_{\mathrm{M}}=\frac{T_{\mathrm{M}}\left(v_{\mathrm{L}}-v_{\mathrm{S}}\right)}{L_{\mathrm{LS}}} \Delta p=C \Delta p=C \frac{F}{\pi 2 R d}
$$

where $T_{\mathrm{M}}$ is the melting point of ice under normal conditions $=273.15 \mathrm{~K}, v_{\mathrm{L}}, v_{\mathrm{S}}$ are the specific volumes of the liquid and the solid phases, $L_{\mathrm{LS}}$ is the specific latent heat of fusion, and $C \approx 7.4 \times 10^{-8} \mathrm{~K} \mathrm{~m}^{2} \mathrm{~N}^{-1}$.

The equilibrium penetration depth $d$ is reached if $\Delta T_{\mathrm{M}}$ is equal to the negative particle temperature $\delta$ in ${ }^{\circ} \mathrm{C}$.

$$
d=\frac{7.4 \times 10^{-8} F}{2 \pi R \delta} .
$$

The corresponding contribution to the total bond volume is similar to Equation (18).

\section{Heat flow}

The heat flow from the growing bond volume (refreezing of the liquid) to the different sources of the liquid (pressure melting, surface flow) limits the possible equilibrium growth rate of the bond volume. The supercooled liquid in the bond volume refreezes at a speed proportional to its supercooling. For a rough estimate, we assume that the liquid refreezes from the sphere's surfaces into the bond volume. The maximum possible refreezing distance is equal to $h$ (Fig. 5). 
The radius of the refrozen bond is approximately

$$
\begin{gathered}
r_{\mathrm{s}} \approx \sqrt{2 R(h+d)}, \quad R \gg h+d \\
h=\frac{r_{\mathrm{s}}^{2}-2 R d}{2 R} .
\end{gathered}
$$

With a linear refreezing velocity $v_{\mathrm{G}}=g \delta$ ( $g$ is the factor of proportionality and equals $10^{-4} \mathrm{~m} \mathrm{~s}^{-1} \mathrm{deg}^{-1}$, Bilgram and Güttinger, 1978) we get an approximate value for the corresponding heat flow $\Phi$ by multiplying an approximate bond surface area by the refreezing velocity and the specific latent heat $L_{\mathrm{LS}}\left(=3.35 \times 10^{8} \mathrm{~J} \mathrm{~m}^{-3}\right)$ :

$$
\Phi=2 \pi r_{\mathrm{s}} \frac{r_{\mathrm{s}}^{2}-2 R d}{2 R} g \delta L_{\mathrm{LS}},
$$

for $V \gg 0$ and $r_{\mathrm{s}} \gg \sqrt{2 R d}$ this equation may be rewritten

$$
\Phi \approx L_{\mathrm{LS}} \pi \frac{r_{\mathrm{s}}^{3}}{R} g \delta .
$$

The heat flow between source and sink is roughly

$$
\Phi=k \frac{\Delta}{b} A
$$

where $b$ is the distance between source and sink, $k$ is the heat conductivity $\left(=2 \mathrm{~J} \mathrm{~m}^{-1} \mathrm{~s}^{-1} \mathrm{deg}^{-1}\right)$, $\Delta$ is the temperature difference between source and sink, and $A$ is the cross-sectional area for heat flow. $A$ is of the order of magnitude of the bond cross-sectional area $\pi r_{\mathrm{b}}^{2}, b$ is approximately equal to $L$ (flow distance). Equations (22) and (23) yield for the temperature difference $\delta$ between source and sink

$$
\Delta \approx 1.7 \times 10^{4} \frac{r_{\mathrm{b}}}{R} L \delta \quad\left(r_{\mathrm{s}} \approx r_{\mathrm{b}}\right)
$$

For the initial states of sintering with $r_{\mathrm{b}} / R \ll 1, L \ll R$, and $\left(r_{\mathrm{b}} / R\right) \mathrm{L}<10^{-4} \mathrm{~m}$, the temperature difference $\Delta$ between source and sink is always small compared with $\delta$ (temperature below the melting point in ${ }^{\circ} \mathrm{C}$ ) for $\delta>0.1 \mathrm{deg}$ and contact times $>2 \mathrm{~s}$.

Thickness of the liquid-like layer

Fletcher (1962) and Golecki and Jaccard (1977) propose a logarithmic dependence of the transition layer thickness $l$ on supercooling:

$$
l=\left(C_{1}-C_{2} \log \left(C_{3} \delta\right)\right) \times 10^{-9} \mathrm{~m}
$$

Golecki and Jaccard: $C_{1} \approx 100 ; C_{2} \approx 50 ; C_{3}=1 \mathrm{deg}^{-1}$.

The revised model of Fletcher (1968) and the Golecki and Jaccard measurements indicate an even sharper increase of the layer thickness above $-1^{\circ} \mathrm{C}$. Our model calculations agree with the measured data only when the log (thickness-temperature) relationship is modified in the same 
direction (Fig. 6).

$$
l=\left(60+\frac{15}{\left(C_{3} \delta\right)^{2}}-30 \log \left(C_{3} \delta\right)\right) \times 10^{-9} \mathrm{~m} .
$$

This dependence is in rough qualitative agreement with Fletcher's revised model and is in fair quantitative agreement with the measurements of Jellinek (1972) and Golecki and Jaccard (1977).

\section{Approximate solutions}

Basically, Equation (11), which describes the rate of increase of the bond volume, has to be solved for the bond radius $r_{\mathrm{b}}$. Assuming a temperature- and time-independent strength of the bond ice, the cross-sectional area $\pi r_{\mathrm{b}}^{2}$ would be proportional to the measured tensile fracture force.

Unfortunately, the time-dependent variation of the penetration depth $d$ (Equation 15) and the complicated expressions for the bond volume $V$ (Equation 6) and the flow distance $L$ (Equation 13), as well as the additional effects of pressure melting and of the transition layer impede a closed form solution of Equation (11).

However, the following approximate solutions can be found:

With the assumption $d \ll R$ we get the following estimate for $r_{\mathrm{b}}$

$$
r_{\mathrm{b}}=\sqrt{ } R d\left(1+\sqrt{\left(1+V / R d^{2}\right)}\right) .
$$

Using this approximation, the differential Equation (12) can be solved for $d \ll r_{\mathrm{b}}\left\langle R, r_{\mathrm{b}}\right\rangle \sqrt{2 R d}$, $L \approx$ constant (case a), or $L \approx \pi r_{\mathrm{K}}$ (Equation $13 \mathrm{~b}$ ) or $(1 / 2 \sqrt{2 \pi})(i / \tau)^{-1 / 2}(\mathrm{~d} V / \mathrm{d} t)^{1 / 2}>r_{\mathrm{b}} / 2(13 \mathrm{c})$ $\left(r_{\mathrm{b}}=\sqrt{2 R d}\right.$ in the absence of any surface flow). This approximation holds for cases where surface flow is the dominant process for bond growth, neglecting plastic deformation of the contact area. These assumptions are fulfilled for high temperatures and for bond radii small compared with the equilibrium radius $r_{\mathrm{e}}$

$$
\frac{2}{R}-\frac{1}{r_{\mathrm{e}}}+\frac{1}{r_{\mathrm{K}}}=0
$$

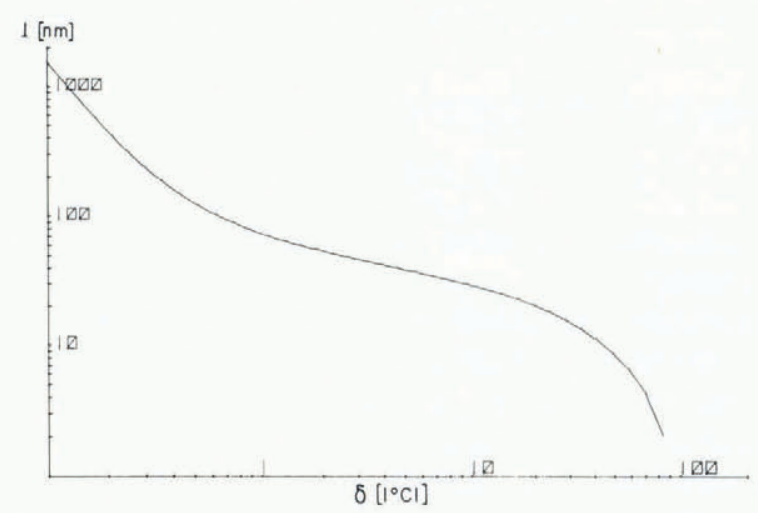

Fig. 6. Thickness of the transition layer as a function of temperature $\delta$. 
where

$$
d \ll R \quad \text { and } \quad r_{\mathrm{e}}=\left(\frac{3}{4}+\sqrt{2}\right) R .
$$

Rewriting Equation (12) for $L$ constant gives:

$$
\begin{gathered}
\frac{\mathrm{d} V}{\mathrm{~d} t}=C^{\prime} \frac{1}{L} r^{*}\left(\frac{2}{R}-\frac{1}{r_{\mathrm{b}}}+\frac{1}{r_{\mathrm{K}}}\right) \\
C^{\prime}=\frac{2 \pi}{3} l^{3} \frac{\gamma_{\mathrm{LV}}}{\eta_{1}} .
\end{gathered}
$$

For $L=\pi r_{\mathrm{K}}$ :

$$
\frac{\mathrm{d} V}{\mathrm{~d} t}=C^{\prime} \frac{1}{\pi r_{\mathrm{K}}} r^{*}\left(\frac{2}{R}-\frac{1}{r_{\mathrm{b}}}+\frac{1}{r_{\mathrm{K}}}\right) .
$$

For $L \approx \frac{1}{2 \sqrt{2 \pi}}\left(\frac{i}{\tau}\right)^{-1 / 2}\left(\frac{\mathrm{d} V}{\mathrm{~d} t}\right)^{1 / 2}:$

$$
\frac{\mathrm{d} V}{\mathrm{~d} t}=\left(C^{\prime} 2 \sqrt{2 \pi}\left(\frac{i}{\tau}\right)^{1 / 2}\right)^{2 / 3}\left(r^{*}\left(\frac{2}{R}-\frac{1}{r_{\mathrm{b}}}+\frac{1}{r_{\mathrm{K}}}\right)\right)^{2 / 3}
$$

where $r_{\mathrm{K}} \approx r_{\mathrm{b}}^{2} / 2 R$ (Equation 3),

$$
\begin{aligned}
& r_{\mathrm{b}} \approx(R V)^{1 / 4} \text { (Equation 27), } \\
& r^{*} \approx r_{\mathrm{b}}+r_{\mathrm{K}} \text { (Equation 4). }
\end{aligned}
$$

For these very limiting assumptions we get for the bond radii

$$
\begin{aligned}
& r_{\mathrm{b}} \approx\left(\frac{5}{2} \frac{C^{\prime}}{L}\right)^{1 / 5} R^{2 / 5} t^{1 / 5}, \\
& r_{\mathrm{b}} \approx\left(\frac{7}{\Pi} C^{\prime}\right)^{1 / 7} R^{3 / 7} t^{1 / 7},
\end{aligned}
$$

and

$$
r_{\mathrm{b}} \approx\left(\frac{7}{6}\right)^{3 / 14}\left(8 \pi C^{\prime}\right)^{1 / 7}\left(\frac{i}{\tau}\right)^{1 / 4} R^{5 / 14} t^{3 / 14} .
$$

The corresponding tensile fracture forces are

$$
F_{\mathrm{T}}=\sigma_{\mathrm{I}}(t, T) r_{\mathrm{b}}^{2} \pi
$$

where $\sigma_{\mathrm{I}}$ is the tensile strength of the bond ice for the given stress distribution as a function of contact time and temperature.

The time and temperature dependence of $\sigma_{\mathrm{I}}$ is not known, therefore, we assume $\sigma_{\mathrm{I}}$ to be independent of the age of the ice as well as of temperature. For the tensile fracture force the power of the contact time $t$ varies for the different models for the flow distance $L$ between $\beta=$ 0.29 and 0.43 . The power of the grain radius $R$ varies from 0.71 to 0.86 . The numerical solution will show that the effective values are lowered by the plastic deformation process. For $t=1 \mathrm{~s}$, $\gamma_{\mathrm{LV}}=0.1 \mathrm{~J} \mathrm{~m}^{-2}, \quad \eta_{\mathrm{L}}=2.5 \times 10^{-3} \mathrm{~kg} \mathrm{~m}^{-1} \mathrm{~s}^{-1}, \quad R=5 \times 10^{-4} \mathrm{~m}, \quad \delta=1 \mathrm{deg}, \quad l=8 \times 10^{-8} \mathrm{~m}$, $L$ (const.) $=3 \mu$ (Equation 30a), $i=5 \times 10^{-7} \tau$ (Equation 30c), the bond radius varies from $55 \mu \mathrm{m}$ 


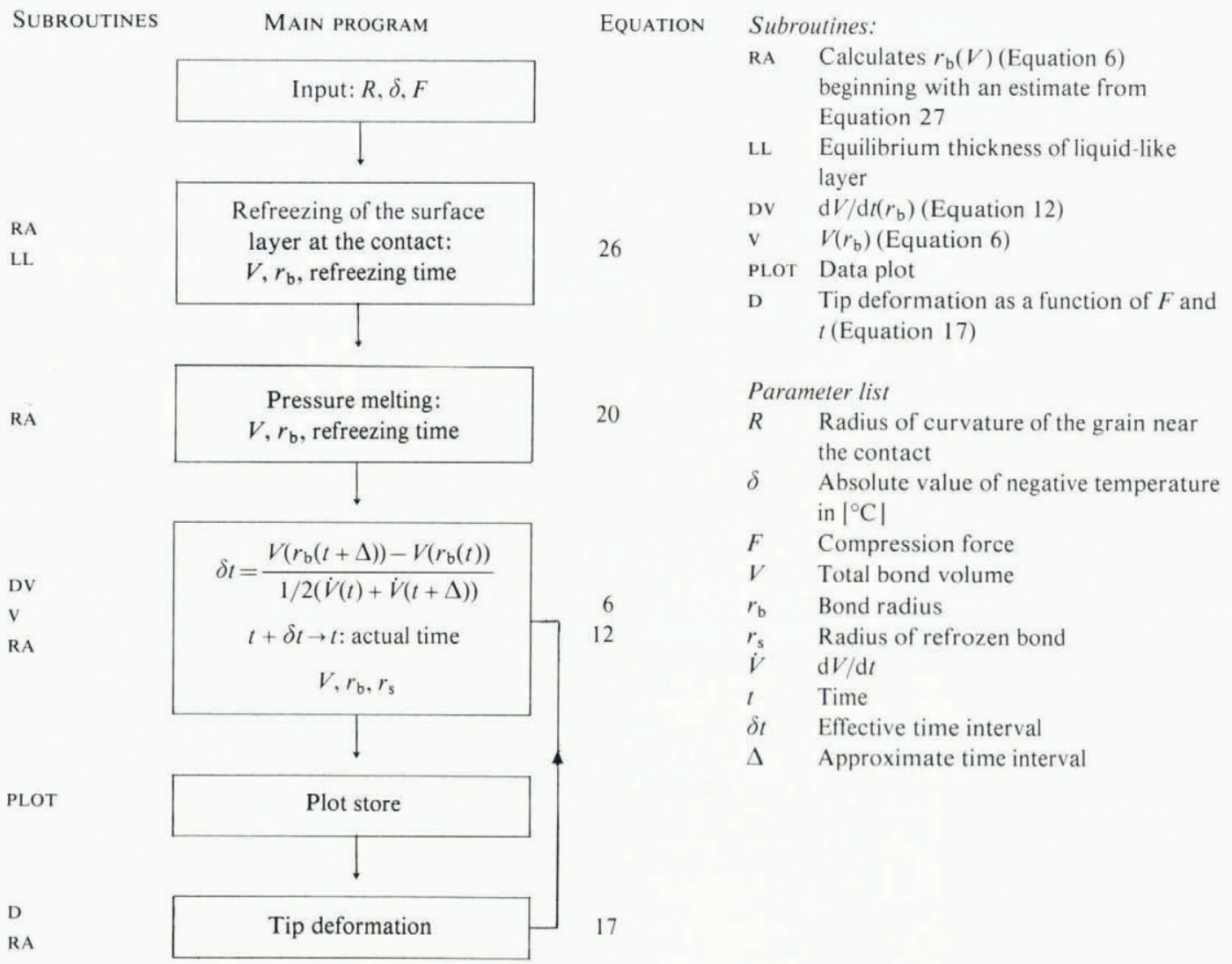

Fig. 7. Flow diagram for the numerical solution.

to $75 \mu \mathrm{m}$. With an ice bond strength of $10^{6} \mathrm{~N} \mathrm{~m}^{-2}$ at a stress rate of about $10^{6} \mathrm{~N} \mathrm{~m}^{-2} \mathrm{~s}^{-1}$ the tensile fracture force is in the range of $10^{-2} \mathrm{~N}(\alpha$ in Equation 1). The comparatively low bond ice strength $\sigma_{\mathrm{I}}$ (about $1 / 2$ of the tensile strength measured by Butkovich (1954)) may be caused by the high surface to cross-section ratio of thin bonds, the low age of the bond ice (some seconds old), and the complicated inhomogeneous stress state in the bond cross-section.

At low temperatures the main process is plastic deformation of the cone tips. From Equations (16 and 17) we have

$$
\begin{array}{ll}
r_{\mathrm{b}}^{2} \approx F t^{0.26} & T \geq 263 \mathrm{~K}, \\
r_{\mathrm{b}}^{2} \approx F t^{0.23} & T<263 \mathrm{~K} .
\end{array}
$$

The decrease of the power of $t$ with decreasing temperature from $0.3-0.4$ (viscous flux regime) to 0.23 (plastic deformation reginre) is the main reason for the measured decrease of $\beta$ (Equation 1, Fig. 3). Equation (32), according to my measurements, indicates that for the plastic deformation regime the fracture tensile force is proportional to the compressive force.

In reality, the two regimes are always mixed, plastic deformation being more important in the initial state of sintering and at low temperatures. If there is no compressional force, bond growth 


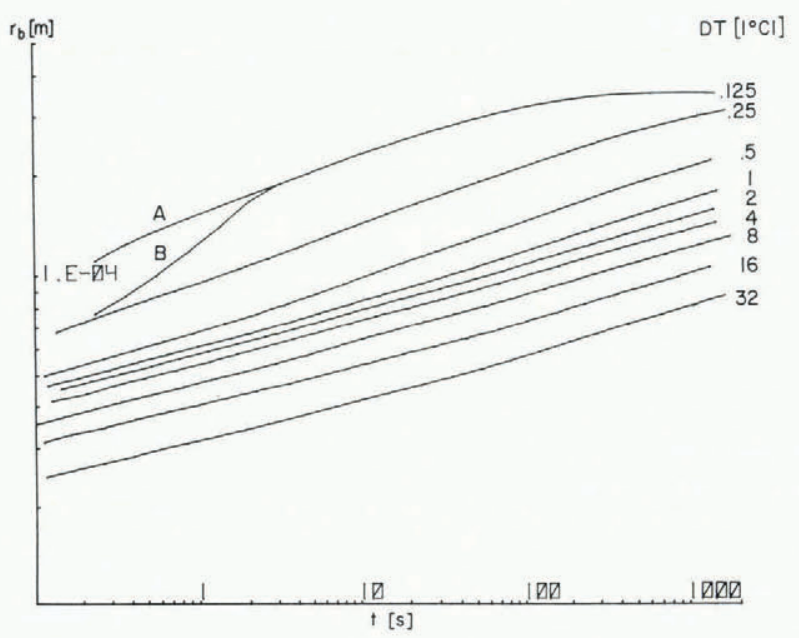

Fig. 8. Calculated bond radius $r_{\mathrm{b}}(\mathrm{t})$ for temperature between $-0.1{ }^{\circ} \mathrm{C}$ and $-40^{\circ} \mathrm{C}$ and a compression pulse amplitude of $10^{-2} \mathrm{~N}$. A: total bond radius. B: radius of refrozen bond.

is completely described by the viscous flow regime for short contact times. For contact times longer than $10^{2}-10^{3} \mathrm{~s}$ the main transport mechanism is vapour transport with a bond-area growth proportional to $t^{0.4}$ (Hobbs and Mason, 1964).

$$
r_{\mathrm{b}}^{2} \approx R^{0.8} t^{0.4} \text { for } t>10^{3} \mathrm{~s} .
$$

\section{Numerical solution}

The flow diagram for the simulation program is given in Figure 7. The program calculates $r_{\mathrm{b}}(t)$ incrementally for given temperatures.

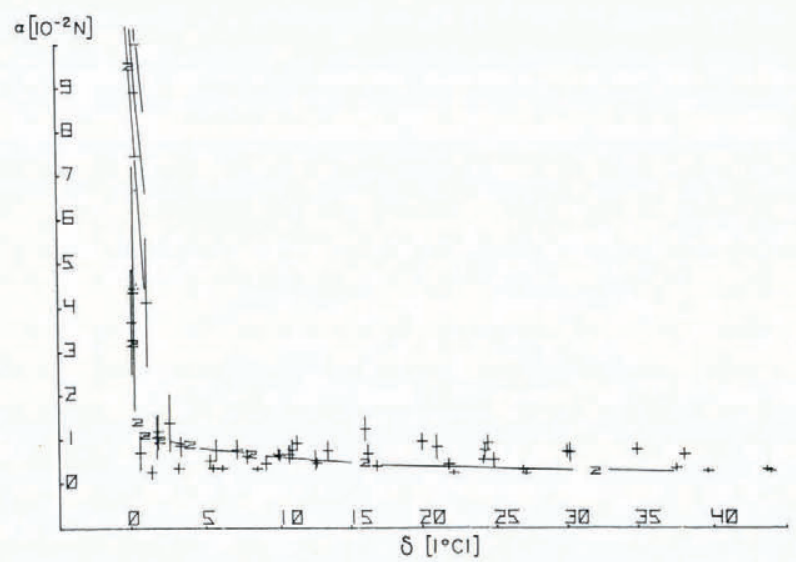

Fig. 9. Tensile fracture force $F_{\mathrm{T}}=\sigma_{\mathrm{I}} \pi r_{\mathrm{b}}^{2}$ as a function of temperature $\delta(2)$ for $t=1 \mathrm{~s}, F=10^{-2} \mathrm{~N}$. Included are the measured data for $\bar{\alpha}$. 


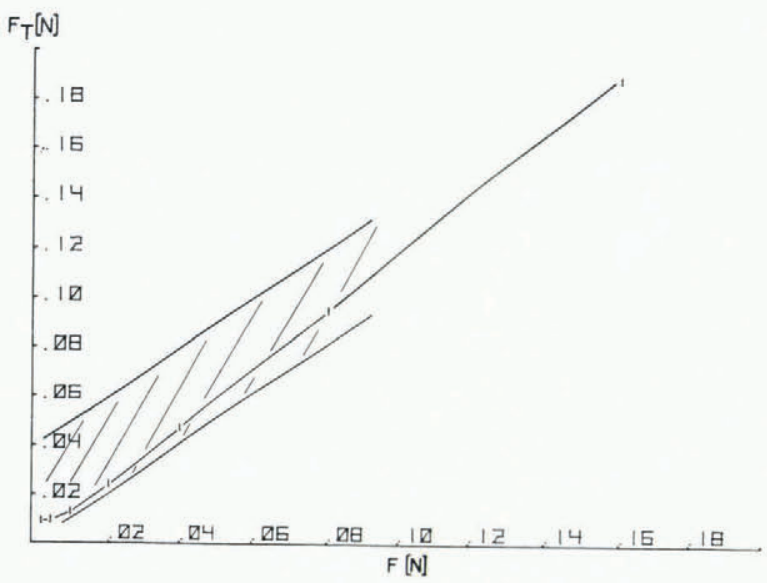

Fig. 10. Calculated fracture force $F_{\mathrm{T}}$ as a function of the compression amplitude $F$ for contact times $t=20 \mathrm{~s}$, $T=263 \mathrm{~K}$. The band shows the range of the measured data (Table I, type B).

\section{Results}

Plots of $r_{\mathrm{b}}(t)$ at different temperatures $\left(F=10^{-2} \mathrm{~N}\right), \sigma_{\mathrm{I}} \pi r_{\mathrm{b}}^{2}(T)$ for $t=1 \mathrm{~s}, F=10^{-2} \mathrm{~N}$; $\sigma_{\mathrm{I}} \pi r_{\mathrm{b}}^{2}(F)$ for $t=20 \mathrm{~s}, T=263 \mathrm{~K} ; \beta(T)$ for $F=10^{-2} \mathrm{~N}, 1 \mathrm{~s}<t<300 \mathrm{~s}$ are presented in Figures 8-11 and compared with the experimental data.

Equation (13c) was used for the model calculation presented here (constant relaxation time at the interface between transition layer and bulk ice). The parameters are given below:

$$
\begin{aligned}
& \frac{\gamma_{\mathrm{LV}}}{\eta_{\mathrm{L}}}=40, \gamma_{\mathrm{LV}}=0.1 \mathrm{~J} \mathrm{~m}^{-2}, \eta_{\mathrm{L}}=2.5 \times 10^{-3} \mathrm{~kg} \mathrm{~m}^{-1} \mathrm{~s}^{-1}, \\
& R=5 \times 10^{-4} \mathrm{~m}, \\
& \frac{i}{\tau}=5 \times 10^{-7} \mathrm{~m} \mathrm{~s}^{-1}, i=5 \times 10^{-10} \mathrm{~m}, \tau=10^{-3} \mathrm{~s} \\
& \sigma_{\mathrm{y}}=10^{6} \mathrm{~N} \mathrm{~m}^{-2} \\
& l \text { given by Equation }(25) \\
& \sigma_{\mathrm{I}}=10^{6} \mathrm{~N} \mathrm{~m}^{-2} .
\end{aligned}
$$

Correspondence between the experimental data and the theory is at its worst at temperatures above $-5^{\circ} \mathrm{C}$. The maximum theoretical value for the bond growth rate is below $-1^{\circ} \mathrm{C}$. Its value of c. 0.35 (simulation) to 0.4 (flux regime approximation; Equation 30c) is in fair agreement with the experiment. The theoretical value for the growth rate drops off faster with decreasing temperature than does the experimental value. This transition from the flux regime to the plastic deformation regime depends mainly on the temperature dependence of the yield stress $(n, E$ in Equation 14). An increased yield stress at temperatures above $-5^{\circ} \mathrm{C}$ would drastically increase the correspondence between theory and experiment (Fig. 11). Additional, more precise measurements are necessary in this temperature range.

The sharp decrease of $\beta(T)$ (Equation 1) at temperatures approaching the melting point is 


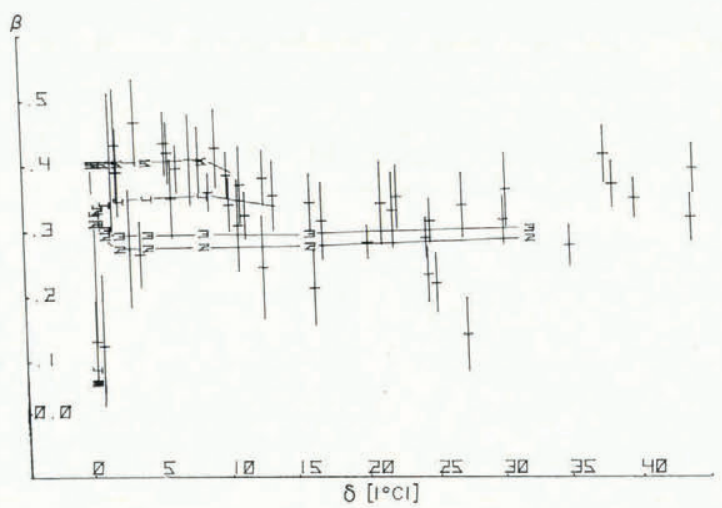

Fig. 11. Calculated and measured values of $\beta(\delta)$ for compression forces $F=10^{-2} \mathrm{~N}$ and compression pulse lengths $1 \mathrm{~s}<t<1000$ s. Measured data $\bar{\beta}$ (Table I, type A); calculated data.

2: $\sigma_{\mathrm{y}}=10^{6} \mathrm{~N} \mathrm{~m}^{-2}, 3: \sigma_{\mathrm{y}}=1.8 \times 10^{6} \mathrm{~N} \mathrm{~m}^{-2}, 4: \sigma_{\mathrm{y}}=4 \times 10^{6} \mathrm{~N} \mathrm{~m}^{-2}, 5:$ Flux regime Equation (30c).

caused by the decreasing pressure gradient in the transition layer for bond radii $r_{\mathrm{b}}$ approaching its saturation value. Because of the large transition layer thickness, bond growth is very fast for temperatures above $-1^{\circ} \mathrm{C}$. However, at temperatures near the melting point, the bonds remain partly unfrozen for contact times up to several seconds (Fig. 8).

The tensile strength of the bond ice is assumed to be independent of temperature. Butkovich (1954) measured a $25 \%$ linear increase in tensile strength between $0{ }^{\circ} \mathrm{C}$ and $-40{ }^{\circ} \mathrm{C}$. In addition, an ageing effect for increasing $t$ possibly increases strength for higher contact times. Both effects, which are not included in the model, tend to increase correspondence between simulation and measurements.

\section{CONCLUSION}

The model describes the development of sintered bonds between ice grains for short contact times and compressive forces in fair agreement with the measurements. Improved measurements of the tensile fracture force $F_{\mathrm{T}}$ and of the bond radius and direct recordings of the deformation $d$ are necessary to refine the model.

\section{ACKNOWLEDGEMENTS}

I should like to thank R. A. Schmidt and K. C. Agrawal for their careful review of the manuscript.

MS. received 1 July 1980 and in revised form 23 September 1981

\section{REFERENCES}

Bilgram, J. H., and Güttinger, H. 1978. Dynamical processes at the ice-water interface during solidification. Journal of Glaciology, Vol. 21, No. 85, p. 537-45. 
Butkovich, T. R. 1954. Hardness of single ice crystals. U.S. Snow, Ice and Permafrost Research Establishment. Research Paper 9.

Faraday, M. 1859. On regelation, and on the conservation of force. Philosophical Magazine, Fourth Ser., Vol. 17, No: 113, p. 162-69.

Fletcher, N. H. 1962. Surface structure of water and ice. Philosophical Magazine, Eighth Ser., Vol. 7, No. 74, p. $255-69$.

Fletcher, N. H. 1968. Surface structure of water and ice. II. A revised model. Philosophical Magazine, Eighth Ser., Vol. 18, No. 156, p. 1287-300.

Gilpin, R. R. 1979. A model of the "liquid-like" layer between ice and a substrate with applications to wire regelation and particle migration. Journal of Colloid and Interface Science, Vol. 68, No. 2, p. 235-51.

Golecki, I., and Jaccard, C. 1977. The surface of ice near $0^{\circ} \mathrm{C}$ studied by $100 \mathrm{keV}$ proton channeling. Physics Letters $A$, Vol. 63A, No. 3, p. 374-76.

Gubler, H. 1978. Determination of the mean number of bonds per snow grain and of the dependence of the tensile strength of snow on stereological parameters. Journal of Glaciology, Vol. 20, No. 83, p. 329-41.

Hobbs, P. V., and Mason, B. J. 1964. The sintering and adhesion of ice. Philosophical Magazine, Eighth Ser., Vol. 9. No. 98, p. 181-97.

Hosler, C. L.. and Hallgren, R. E. 1960. The aggregation of small ice crystals. Discussions of the Faraday Society, No. 30, p. 200-07.

Jellinek, H. H. G. 1972. The ice interface. (In Horne, R. A., ed. Water and aqueous solutions. New York, John Wiley and Sons, Inc., p. 65-107.)

Jensen, D. C. Unpublished. On the cohesion of ice. [M.S. thesis, Pennsylvania State University, 1956.]

Kingery, W. D. 1960. Regelation, surface diffusion, and ice sintering. Journal of Applied Physics, Vol. 31 , No. 5. p. $833-38$.

Kry, P. R. 1975[a]. Quarititative stereological analysis of grain bonds in snow. Journal of Glaciology, Vol. 14, No. 72, p. 467-77.

Kry, P. R. 1975|b|. The relationship between the visco-elastic and structural properties of fine-grained snow. Journal of Glaciology, Vol. 14, No. 72, p. 479-500.

Kuroiwa, D. 1961. A study of ice sintering. Tellus, Vol. 13, No. 2, p. 252-59.

Kvlividze, V. I., and others. 1974. The mobile water phase on ice surfaces, |by| V. I. Kvlividze, V. F. Kiselev, A. B. Kurzayev, and L. A. Ushakova. Surface Science, Vol. 44, No. 1, p. 60-68.

Maeno, N., and Nishimura, H. 1978. The electrical properties of ice surfaces. Journal of Glaciology, Vol. 21, No. 85, p. 193-205.

Nakaya, U., and Matsumoto, A. 1954. Simple experiment showing the existence of "liquid water" film on the ice surface. Journal of Colloid Science, Vol. 9, No. 1, p. 41-49.

St. Lawrence, W. F. 1980. The acoustic emission response of snow. Journal of Glaciology, Vol. 26, No. 94 , p. 209-16.

St. Lawrence, W. F., and Bradley, C. C. [1975.] The deformation of snow in terms of a structural mechanism. [Union Géodésique et Géophysique Internationale. Association Internationale des Sciences Hydrologiques. Commission des Neiges et Glaces.] Symposium. Mecanique de la neige. Actes du colloque de Grindelwald, avril 1974, p. 155-70. (IAHS-AISH Publication No. 114.)

Weyl, W. A. 1951. Surface structure of water and some of its physical and chemical manifestations. Journal of Colloid Science, Vol. 6, No. 5, p. 389-405. 